\title{
FOCUS AWARDS 2003
}
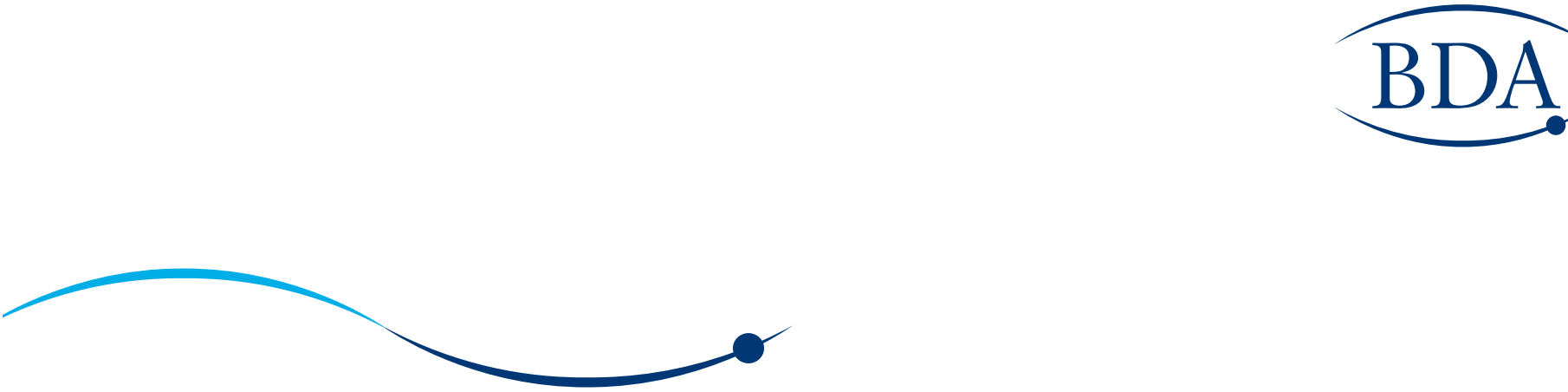

The Focus Awards 2003 recognised continuing excellence in dental patient care across the UK, Wales and Northern Ireland. The award for excellence in creating a patient friendly environment went to Queensferry Dental Surgery, Flintshire; Naomi Davis finds out why.

Queensferry Dental Surgery was set up in 1990 with some very clear ideas about what the practice would be like. The aims of Stu Brown, the practice owner, and his wife Liz, the practice manager, were to build a practice with modern equipment and to keep it in good decorative order. 'We wanted it to feel more like a home', explains Liz. They have achieved these objectives so successfully that they were awarded the 2003 Focus Award for excellence in creating a patient-friendly environment.

\section{PRACTICE OPEN TO ALL}

The practice has been designed to have two accessible surgeries with the aid of a ramp and a hand rail and has fully accessible toilet facilities with a low-level basin.

Every effort has been made to make children feel at home. There are two child-friendly areas each with a lego table and a book shelf. A special company visits the practice every month to collect the toys to professionally clean

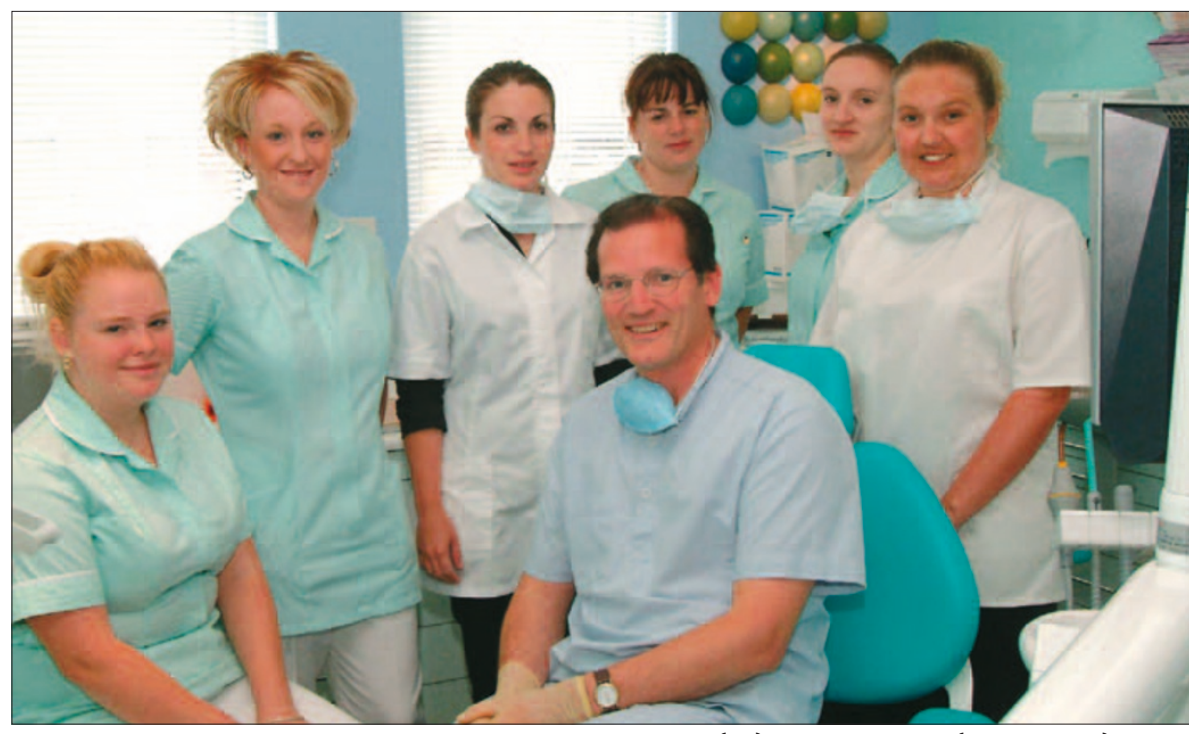

Some of the team from Queensferry Dental Surgery, Flintshire, (I-r) Sarah Rowlands (dental nurse), Tarina Roberts (dental nurse), Elise Evans (dentist), Stu Brown (practice owner), Debbie Cartwright (dental nurse), Helen Bennett (dental nurse) and Sue Murdoch (dentist)

and sterilise them to keep them from getting dirty and scruffy. The lego chairs and tables get the same treatment too.

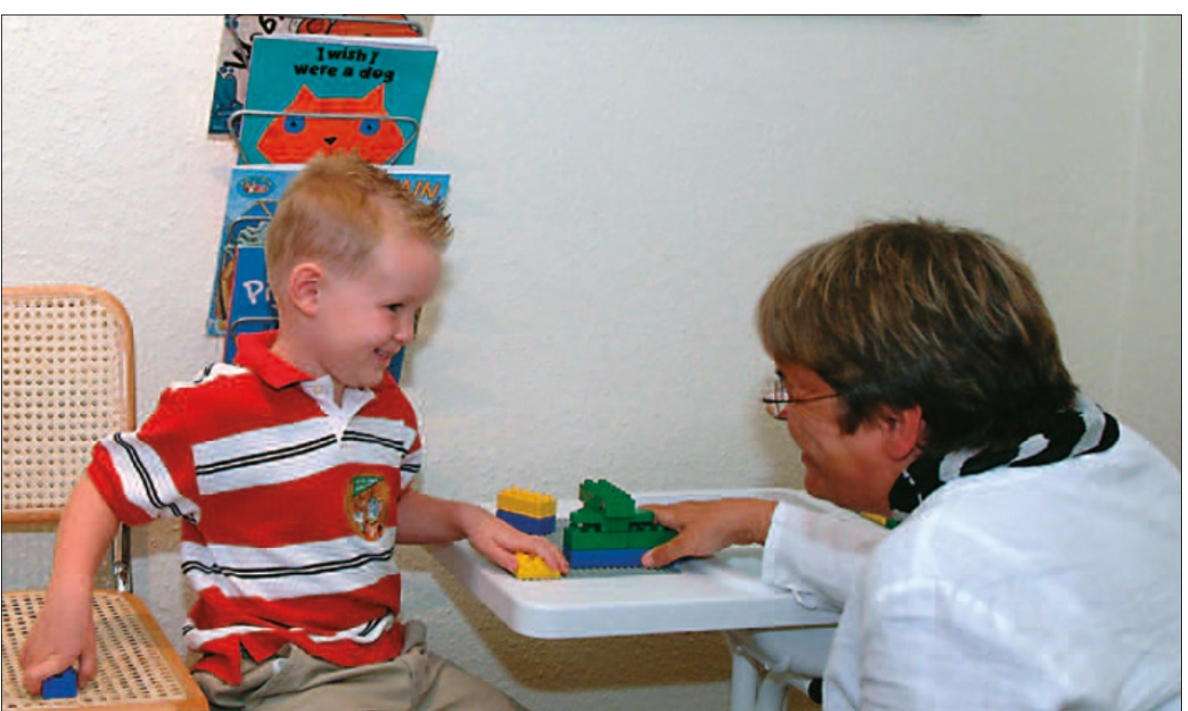

A lego table in each waiting area keeps younger patients amused

\section{RELAXING EVIRONMENT}

More than 50 new patients each month enjoy the relaxing environment at the Queensferry Dental Surgery. There are two large comfortable waiting areas which are kept to a high decorative standard with framed pictures on the walls. The rooms are redecorated every six months, and any pictures or books that are getting old or shabby are replaced and updated. The reception area has a smart granite top which is kept free of screens so patients can see the receptionist clearly.

Peaceful background music helps to maintain a calm atmosphere, which patients can enjoy while reading the daily newspapers and up-to-date magazines available. Mineral water and freshly brewed coffee are available for the patients too.

If the weather is good there is a courtyard which has been renovated and filled with plants; a sanctury for staff and patients. 


\section{(DH) Department
of Health}

The Focus Awards is a joint initiative between the Department of Health for England, the Department of Health, Social Services and Public Safety of Northern Ireland, Welsh Assembly Government and the British Dental Association.
Department of Health, Social Services \& Public Safety Northern Ireland

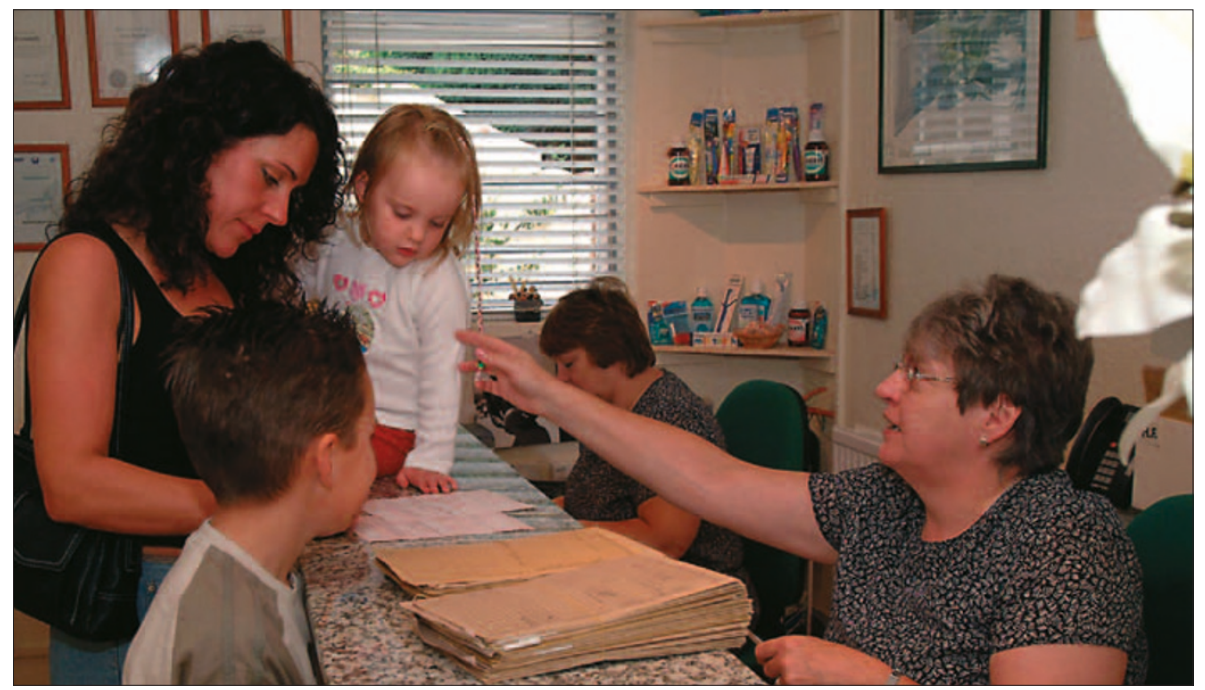

Smart reception area with granite tops. The practice is fully computerised

Each waiting area also has a video screen where educational oral health and healthy eating videos are shown along with useful information about the practice and the dentists in the team. All signs throughout the reception and waiting areas are in both English and Welsh to cater for the bilingual nature of Queensferry's population. There are four surgeries in the practice, all of which are fully computerised and air-conditioned. The patients really like the latest digital camera technology, where proposed treatments can be described using illustrations of the patients' own teeth.

\section{HAPPY PRACTICE, HAPPY TEAM, HAPPY PATIENTS}

Something which sets Queensferry Dental Surgery apart from other practices is their recognition of the link between happy staff and happy patients. They realise that if the practice is an enjoyable place to work, the staff will be happy at work, making the practice an enjoyable and relaxing place to visit.

The approach made by Stu and Liz really seems to be working. Not only were the Focus Award judges impressed, more importantly, so are their patients. One patient makes a 70-mile round trip in heavy traffic to visit this practice, and has done so for the past 13 years. This is down to their confidence in the dentist and the welcome they always receive.

\section{How the teams got involved}

To participate, each entrant submitted a nomination form with documentation supporting their claims of excellence in dental patient care, specifying which category or categories they wanted to be entered for:

- Excellence in children's dental care

- Excellence in treating those with special healthcare needs

- Excellence in patient information and involvement

- Excellence in creating a patient friendly environment

- Excellence in the development of good practice

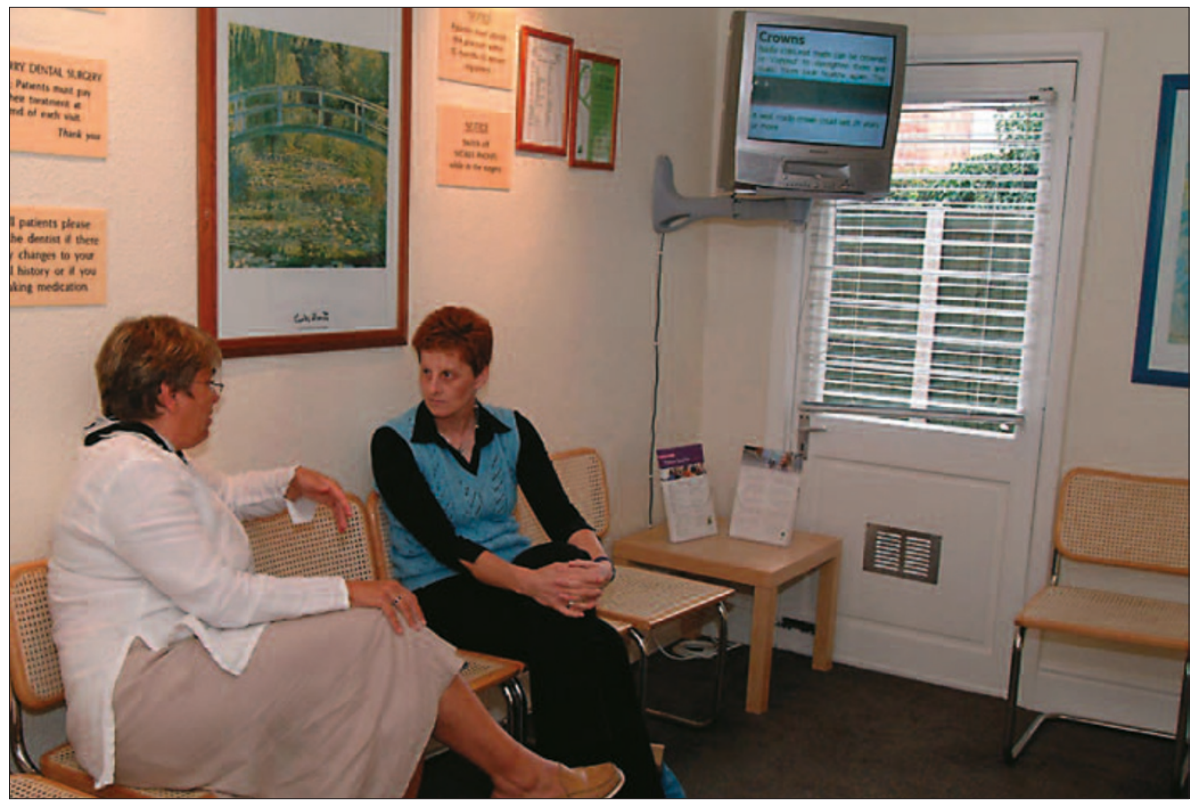

Liz Brown chats to a patient in the waiting room. Each waiting area has a video screen displaying educational and useful information 